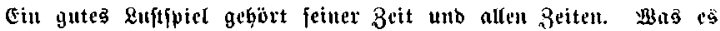

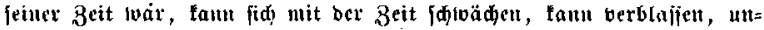
verftänblid loerbest, aber es mus, aud um für bie Zeit, in solder es

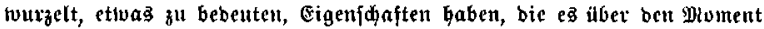

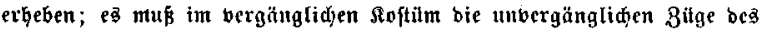
Menfdien, ber an teine Beit gebunbcu ijt, bu trejfen wiffen: nidjt allein bie Safter, wie cinft seffings Jugentlycorie forberte; nidat allein bit

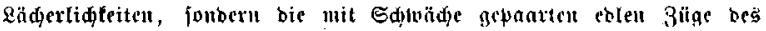
Menjdyen. Denn wic fcin Wenjo blop fnfturyaft ober. läderlid ift, giebt

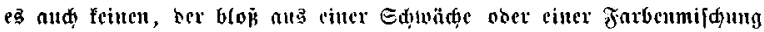

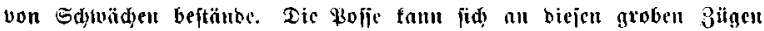

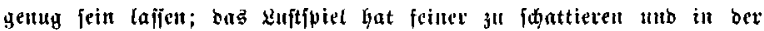

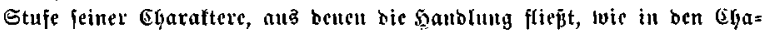
rafteren an jidt bie Seftanbteile lebensioabr all vereiniget, unbefïmmert barum, ob es mirtia folde Ebaraftere giebt, nur bap̃ bie Mröglidfleit

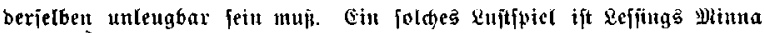

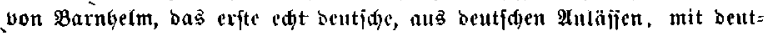

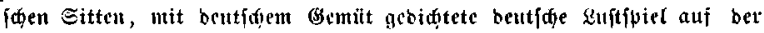

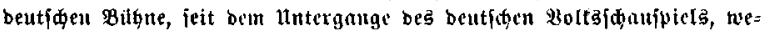

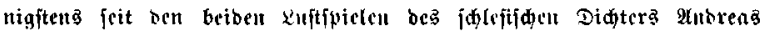
(Sryphius.

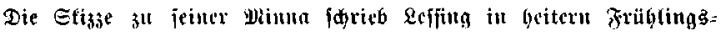

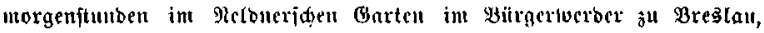
als ex Sefretät bes Gencrals Tautuzicu war, unb arbeitete biejelbe aus,

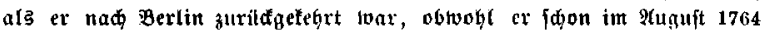

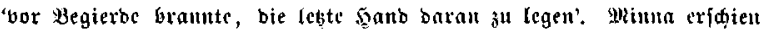
im Jabr 1767 uto wurbe in bemijelben Jahce, nadjocm jie anfangs auf preußifde Berankafiutg beanitaubct ober verboten war, ziterit am 28 . Sept.

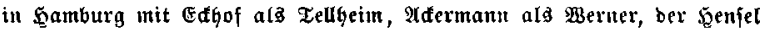

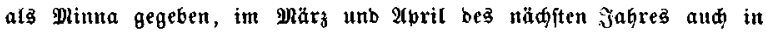
Berlin zehnmal umunterbroden bor cinem vollelt $5 a u f e .2 B_{0}$ hätte bas Stüđ aud freubiger aufgenommen fverben follen, alä in ber Gauptitabt

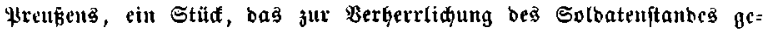
bidjtet war? 


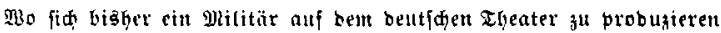

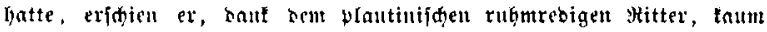

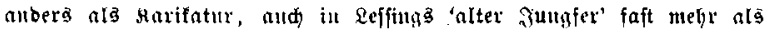

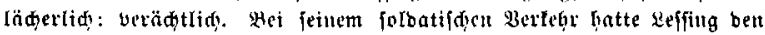
Stanb, Offiatere lwit Eolbaten, atd yon ber guten Eette, als bray, gut=

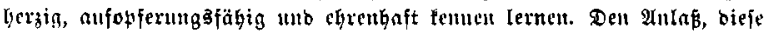

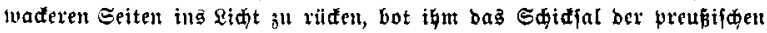

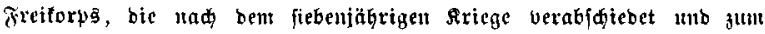
Teil bem bittert Elenbe preisgegeben wurben. H(ş Repräfentanten bcr

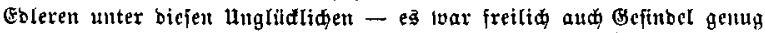

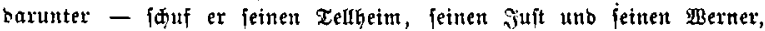
allc brei fo bis in bie fleinften Bilge lebensitoabr auggearbeitet, bap man fdiruant, weldem bon ibnen man ben Borzug geben und ob man mehr bie Arbeit ober bas fertige Probult betwunbern foll. Daneben ben für feinen Berbiemf́t beforgten, aber barüber fintaus aud ju niditz zu vernio= genben neugierigen Birt unb ben leidtfiutigen unb bod Teilnahme et: weferben Miccaut, ber erit zum פitlei beiwegt, nit guter Art nimmt

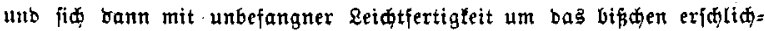
ner Teilnahme bringt. Diejent Männetn gegenüber bic entidlofjene

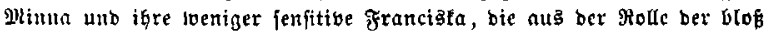

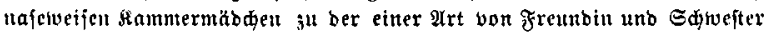

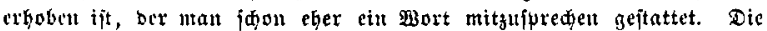

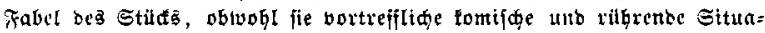
tionen zulvege bringt, ift gegen bie Sharaltere ein twentig idivad ulto

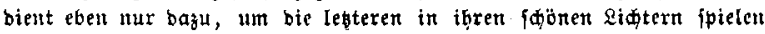

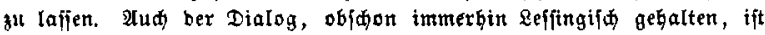
bod ntebs als in anbern Etüđen bes Diditers ben Jnbibionalităten an= gepapt unb belvegt fid ridjt in ben furzen epigranmatifi jugefpig̨ten Säłen, wie in bem nädften bramatifden Erzenguije Refjings.

Das Ruftipiel warbe, naturlid mit ben erforberlifien 'Berbefierun=

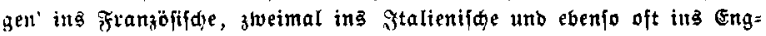
lifide verarbeitet.

\section{Sarl Bnebete.}




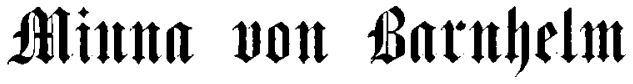 oder}

\section{Dả Soldatengliưf.}

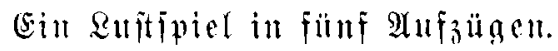

1763. 